\title{
¿QUÉ SIGNIFICA QUE DIOS «ACTÚA» EN LA CREACIÓN?
}

\author{
PEDRO CASTELAO \\ Universidad Pontificia Comillas
}

\begin{abstract}
RESUMEN. Hay algunos presupuestos que dificultan comprender qué quiere decir un creyente cuando afirma que Dios actúa en la creación. Presupuestos compartidos también por quienes niegan sentido a esa afirmación. En este artículo se estudian dichos presupuestos y sus consecuencias teológicas. También se estudian las concepciones naturalistas, supranaturalistas y panenteístas a la hora de pensar la interacción entre Dios y la creación.
\end{abstract}

PALABRAS CLAVE: acción de Dios, naturalismo, supranaturalismo, panenteísmo, Dios, creación.

\section{What does it mean that God «acts» in creation?}

ABSTRACT. There are some assumptions that make difficult to understand what the believers wants to say when they say that God acts in the Creation. Those assumptions and their theological consequences are studied in this article. The naturalistics, supranaturalistics and panenteistics conceptions are also studied considering the interaction between God and Creation.

KEY WORDS: God's action, Naturalism, Supranaturalism, Panentheism, God, Creation.

Comencemos con una engañosa obviedad. Las personas que creen en la existencia de Dios creen, de una u otra manera, que Dios está presente y actúa en el mundo. Las personas que no creen en la existencia de Dios creen lo contrario, a saber: que Dios ni existe ni actúa de ninguna forma en el mundo.

El problema radica en saber qué se entiende aquí por «Dios», por «actuación» y por "creación». Y es que se concitan tras este planteamiento tan simple un gran número de presupuestos cuya importancia conviene no despreciar, puesto que se trata de peligrosos prejuicios que, fatalmente, confunden todo. Estos prejuicios son especialmente graves porque son - curiosamente-compartidos por ambas posturas. Situados creyentes e increyentes en este terreno común, no hay forma de escapar a las falsas consecuencias que se derivan tanto en un sentido como en el contrario. De entre todos estos prejuicios destaco, principalmente, tres: a) La reificación de «Dios» como un sujeto supremo; b) La antropomorfización de su «actuación»; c) La autonomía clausurada de la «creación».

a) Cuando el concepto de «Dios» aparece privado de la lógica propia de los símbolos religiosos su referente resulta profanado por la peor de las profanaciones: aquella que, precisamente, cree haberlo comprehendido y retenido con sólo nombrarlo. "Dios» no es un sujeto susceptible de ser mentado y referido como el resto de sujetos y objetos intramundanos. Eso no es más que una involuntaria y vulgar reificación. Dicha reificación puede darse en una eventual afirmación de su existencia — comprendida ésta como la sobrenatural naturaleza de un Ser Supremo elevado sobre el mundo en el más excelso grado- o bien en la 
negación de su existencia - comprendida ésta como la ausencia absoluta de ese mismo Ser Supremo. En ambos casos Dios ha dejado de ser Dios para verse reducido y confundido con el ápice sobresaliente de un sistema de pensamiento y realidad sólo inmanente. Tal concepción de Dios mutila y desfigura su configuración esencial como Misterio Santo que permanece misterio — realidad absoluta e inabarcable- en su máxima revelación.

b) Cuando el concepto de «Dios» resulta objetivado también se contamina la idea de su «actuación». La praxis divina deviene igualmente profanada al ser comprendida según los cánones del actuar intramundano. Toda acción supone un cambio del reposo o la inacción a la realización en acto de la actuación querida. Se trata siempre, y más en el caso de la acción humana, de un tránsito de la voluntad. Aplicada tal concepción a la realidad de Dios surge la insoslayable imagen de un Dios inicialmente ocioso y expectante mutando, seguidamente, hacia la de un Dios puntualmente activo, antes de regresar, nuevamente, a su natural y sabática inactividad. Que Dios «actúe» en la creación significaría para los creyentes su puntual intervención en un momento concreto del tiempo y en un lugar determinado del espacio precedida de su inacción y seguida por el retorno a la inactividad. La negación de dicha actuación comparte en todo la descripción antedicha con la única salvedad de que niega que tal cosa se dé. Pensar en dichos términos la actuación de Dios en el mundo es idolatría, porque no es el actuar divino el que se piensa, sino un actuar intramundano que usurpa la verdadera «acción» de Dios.

c) Cuando el concepto de «Dios» y su «actuar» son objetivados no sale bien parada ni la propia realidad de la creación. Llamamos «creación» a la totalidad de lo que existe, al conjunto completo de todo aquello que tiene entidad en el espacio y el tiempo por más lejano y desconocido que pueda ser respecto de nuestra minúscula existencia. Pues bien, la creación resulta clausurada y desdibujada cuando se pretende que su relación con Dios —en caso de que tal cosa se désea del tipo de relación que caracteriza la alteridad de los entes singulares. Esto no es lo otro, y lo de más allá se diferencia de aquello, porque ni esto, ni lo otro, ni aquello ni lo de más allá son lo mismo. Su alteridad es la base de su diferencia. Su diferencia la base de su identidad. Y su identidad la base de que todos los entes puedan pensarse como un todo conjunto que, no obstante, no ignore ni anule su irrepetible singularidad. ¿Puede este conjunto, pensado como un todo con interna diversidad, ser relacionado con otra entidad distinta de Él —Dios como Ser Supremo- susceptible, a su vez de ser nuevamente englobados en una locución que los nombre como lo uno - la creación - y lo otro - Dios- o viceversa? ¿Es posible situarse especulativamente en un neutro tercer lugar desde el cual poder contemplar y nombrar la eventual relación existente entre ese primer actor llamado «Dios» y ese producto de su «actuación» llamado «creación»? ¿Son numéricamente dos «Dios» y la «creación»? ¿Hacemos lo correcto al pensar la autonomía de la creación en alteridad frontal respecto de su origen y fundamento?

Concretando, pues, un poco más nuestro inicial punto de mira podríamos decir, por razones que luego se verán, que hay tres modos de enfocar la cuestión de la presencia y actuación de Dios en la realidad teniendo muy en cuenta todo cuanto acabamos de señalar: el «naturalismo», el «supranaturalismo» y lo que podríamos llamar «panenteísmo dialéctico». 


\section{Naturalismo}

Llamo naturalismo a aquella concepción del mundo que sostiene que existe única y exclusivamente aquello que es susceptible de ser observado, medido o experimentado. El naturalismo es, por una parte y en cierto sentido, una gran conquista de la modernidad, puesto que, con la matematización de la naturaleza, ha desterrado al mundo de los sueños y la imaginación a realidades ilusorias que antes se consideraban como causas efectivas de sucesos cotidianos.

No obstante, este innegable triunfo del naturalismo ha tenido una consecuencia contundente para toda experiencia religiosa. De un mundo que funciona de manera autónoma en su acontecer natural, ¿puede decirse que «actúa» Dios en él? Y en caso de una respuesta positiva: ¿cómo afirmar la presencia y actuación de Dios en el mundo, habida cuenta de que, en diálogo con la ciencia actual, la forma tradicional de pensar dicha actuación y presencia —intervencionista y arbitraria - resulta de todo punto inadecuada?

Cuando un naturalista investiga el mundo Dios no aparece por ningún lado. Ni a través del microscopio entre las nanopartículas subatómicas ni a través del telescopio junto a la última estrella de la última galaxia de la última constelación visible. ¿Significará, pues, el naturalismo el triunfo definitivo de la increencia frente a esa «ilusión» de un Dios presente y actuante?

Existe una espiritualidad naturalista que, para contrarrestar esa apurada conclusión, tiende a identificar a Dios y su presencia con el natural y esencial desarrollo del mundo. Dios vendría a ser, pues, esa presencia total y completa - en una llamada dimensión holística - en continuo movimiento y continua quietud que no se diferencia del cosmos mismo ya que no es sino su más profunda y esencial constitución. Lo que las gotas de agua son al océano somos las criaturas al piélago de la divinidad. Una divinidad libre de contornos y perfiles extendida en su ser como desplegadas y extendidas están las constelaciones del universo.

El naturalismo sostiene la ausencia de Dios en el mundo. La teología naturalista responde: Dios no está, ciertamente, en el mundo ni actúa en él porque la divinidad es el propio mundo y, por tanto, no hay necesidad de hablar de la «acción» de Dios en él, a no ser como identidad sin diferencia entre el actuar del mundo y el propio «actuar» de Dios.

\section{Supranaturalismo}

El supranaturalismo se resiste con uñas y dientes a la apurada conclusión del naturalismo y rechaza ferozmente su teología y espiritualidad. Y lo hace en dos versiones. Una clásica y una más actualizada. La primera es tradicional y muy clara. La segunda es más fina y moderna y, por ello, puede parecer más atractiva.

\subsection{Versión clásica}

En su primera versión el supranaturalismo nos dice que Dios sí actúa en la creación, que está presente en ella y, para hacerlo, suspende, cuando lo considera 
necesario, el acontecer ordinario de los fenómenos del mundo para hacer algo literalmente «extraordinario». Dios es Señor del mundo y gobierna a su antojo sobre él.

Esta es la concepción apologética y decimonónica — que no bíblica- del milagro. ¿Cómo actuaría Dios en el mundo? El supranaturalismo tradicional responde: interrumpiendo el modo normal de suceder las cosas contraviniendo así las mismas leyes que el creador de la naturaleza ha establecido. El presupuesto aquí presente es claro: Dios no está en el mundo, está fuera de él y, para hacerse presente en él tiene que hacerse un hueco en el entramado del mundo anulando o impidiendo que el mundo funcione como suele hacerlo de forma ordinaria.

Es capital señalar, aunque ya se habrá advertido, que el naturalismo y el supranaturalismo comparten - fatalmente- el mismo presupuesto: Dios no está en el mundo. Y sólo se diferencian en que uno niega su presencia puntual, fragmentaria y excluyente - ya que Dios sería el mismo mundo para la espiritualidad naturalista- mientras el otro, el supranaturalismo, afirma esa presencia puntual, fragmentaria y excluyente contra viento y marea.

\subsection{Versión moderna}

Últimamente se ha puesto muy de moda sostener una versión actualizada del supranaturalismo clásico. Se afirma, por ejemplo, que Dios respeta la autonomía de las leyes de la naturaleza y ni las interrumpe ni las anula en su matemático acontecer, sino que su actuación y su presencia habría que buscarla, más concretamente, en los ámbitos de indeterminación de la mecánica cuántica o, más en general, en todo proceso regido únicamente por la probabilidad en el que parezca imperar el «azar».

Ahora bien, situar la acción divina en ámbitos o en procesos intramundanos no susceptibles de una determinación causal predecible es, por lo pronto, una simple variación de la posición supranaturalista clásica que en nada modifica su presupuesto fundamental. Contraponer el acontecer regular de unos procesos intramundanos al acontecer azaroso de otros y, asumir que los primeros no son aptos para reconocer en ellos la «acción de Dios», de forma que sí parecería que sólo pudieran serlo los segundos, es un planteamiento del problema de fondo -qué es "acción" de Dios- que incurre, ya desde el principio, en la asunción del mismo presupuesto teológicamente inadecuado que hemos visto en la versión tradicional.

Este presupuesto, como estamos viendo, es el siguiente: la «acción de Dios» sería completamente concurrente —en su puntual, fragmentario y excluyente acaecer- con los procesos intramundanos. Si Dios actúa, la creación queda anulada. Si actúa la creación, Dios ni puede actuar ni puede estar presente. En consecuencia, Dios sólo podría actuar en el mundo en los «vacíos», en los «huecos» o en los «agujeros» de indeterminación de cualquier proceso físico. Esta concepción —por muy moderna y actual que parezca- presupone que la acción de Dios sería incompatible con procesos regulares susceptibles de ser descritos con leyes físicas traducibles a fórmulas matemáticas fijas y que, por el contrario, — conviene insistir en ello- la acción de Dios podría ser armonizable solo con procesos abiertos o indeterminados únicamente referibles a través de estadísticas o fórmulas de probabilidad. Es necesario subrayar que dicho planteamiento implica una gravísima desdivinización 
de la acción divina porque, en el fondo, la sitúa en el mismo plano de actuación que la de todos los procesos intramundanos. Ya sea privilegiando unos (azar), ya rechazando otros (regularidad).

\section{3. «PANENTEísmo diaLÉctico»}

Si la «acción de Dios» en el mundo y, por tanto, su presencia es efectivamente de Dios - a saber: si es realmente divina - entonces, ha de ser absolutamente trascendente a todo cuanto acontece y existe, al tiempo que absolutamente inmanente a todo proceso intramundano. Lo cual significa que se encuentra a igual distancia - en la máxima cercanía de la inmanencia y en la total diferencia de la absoluta trascendencia - tanto de los procesos regulares como de los azarosos o indeterminados sin poder identificarse ni confundirse con ninguno de ellos. Este movimiento dialéctico que acabo de señalar es absolutamente capital.

Azar y regularidad nómica, por tanto, han de ser pensados de forma conjunta (y no disyuntiva) a la hora de plantear la cuestión de la acción de Dios y de su providencia en la historia del mundo.

La razón de esto es que tanto el azar como la regularidad describen fenómenos propios de una creación que, según la fe cristiana, toda ella —en su azar y necesidad, en su materia y espíritu, en su principio y en su fin- procede de Dios. Dicho de otro modo: todos los fenómenos creaturales — según la teología cristiana - tienen en su inicio absoluto, en su presente más íntimo y en su futuro definitivo el impulso, el sostén y la orientación del amor incondicional del Dios creador.

Con todo, hay que reconocer que el supranaturalismo acierta cuando, frente a la reducción naturalista, intenta salvaguardar la trascendencia de Dios señalando que sólo Dios es Dios y que, por lo tanto, Dios no es ni una realidad mundana ni la totalidad de los procesos del mundo. Se equivoca, sin embargo, cuando para salvaguardar la trascendencia de Dios respecto al mundo, acepta compartir el mismo presupuesto que el naturalismo respecto de la ausencia de Dios del mundo negando, así, la inmanencia de Dios en él.

Por su parte, el naturalismo también es correcto cuando, frente a la heteronomía arbitraria del supranaturalismo, intenta salvaguardar la autonomía de la creación señalando que el cosmos es susceptible de matematización y que el principio de razón suficiente excluye causalidades puntuales que se refugien más allá de lo empíricamente constatable. Pero se equivoca cuando piensa que, si no se afirma de Dios un modo de presencia y actuación puntual, fragmentaria y excluyente, entonces no hay más salida que o bien negar su existencia o, de afirmarla, identificarla sin diferencia — es decir: confundiéndola — con la totalidad de los fenómenos de la naturaleza.

Ante este dilema sólo cabe, a mi juicio, la posición del «panenteísmo dialéctico»: Dios está en todas las cosas y no hay ninguna de ellas privada de la presencia y actuación de Dios en ella — debido a su absoluta inmanencia- sin que, no obstante, Dios pueda ser identificado ni confundido con ninguna de ellas — habida cuenta de su absoluta trascendencia-. Ahora bien, ¿qué significa todo esto y qué consecuencias prácticas puede tener? 


\title{
4. CONCLUSIÓn
}

\author{
¿Cómo actúa Dios en la creación? En primer lugar, dando el ser a todo cuanto \\ existe. \\ En segundo lugar, manteniéndolo en el espacio y el tiempo a lo largo de todo su \\ histórico discurrir.
}

Y en tercer lugar, orientándolo hacia la plenitud escatológica de su amor.

Dios no actúa en el mundo «contra» la creación o "contra» la libertad humana, sino a través de ella potenciando su autonomía y su propio ser. Pero esto es algo que ni se ve ni se nota, por lo menos, en una vivencia apresurada de la vida. Y es que se necesita soledad, silencio y oración para poder percibir a Dios como el Misterio Sagrado que alienta en la creación tras el zumbido del viento, la calidez del sol, la inmensidad del océano o la solidez de las montañas sin ser, no obstante, ni aire, ni fuego, ni agua, ni tierra. Y es que Dios no es un elemento, ni la quintaesencia de los elementos. No es ente, sino la fuente originaria de todo ente. No es ser, sino aquel que trasciende, fundamenta y supera en plenitud y significación a todo ser. Y por ello puede tener carácter personal sin quedar preso en las limitaciones y ambigüedades de nuestro ser personal. Dios no es una persona. Ni la suma de tres individualidades. Es la plenitud perfecta en la vivencia del amor del carácter personal que emerge en nosotros, pero que Él vive en la eternidad más allá de las mezquindades y dobleces que oscurecen nuestro corazón. Ni la soledad del uno — contrapuesto al mundo-, ni el antagonismo de la díada — siempre bordeando el dualismo originario-, ni la apertura de la tríada — aquejada de dispersión. Unidad y multiplicidad han de ser aquí trascendidas como símbolos religiosos que remiten a una plenitud inimaginable de la que ningún concepto humano puede dar cuenta de forma total y completa. No obstante, el cristianismo no nos deja atónitos y mudos frente al Misterio Absoluto como si únicamente fuese silencio o vacío. El silencio o el vacío son modos de llegar a Él. Y en Él habitan el Logos y el Espíritu. El Espíritu que alienta en la creación y el Logos que la informa y estructura. Realidades divinas estas que el cristianismo ha sabido ver presentes y actuantes en la historia de la revelación y muy especialmente en las palabras y obras de Jesús de Nazaret. Ese Jesús que vinculó indisolublemente el insondable Misterio de Dios con el amor del Padre que sólo puede querer el bien de aquellos a quienes ama. El bien incondicional y absoluto.

Es así, pues, que según la sabiduría cristiana Dios está presente y actuante en todas aquellas realidades y libertades que en el mundo cooperan para el bien. Sana y cura a través de las acciones de misericordia, p. e., de todos los samaritanos del mundo que, desviándose de su camino, socorren a quienes yacen en la cuneta.

¿Quién actúa cuando actúa el caminante de Samaría? El samaritano, se dirá con toda razón. ¿Sobre quién actúa dicho samaritano? Sobre un desconocido herido al borde del camino. ¿No hay en ese hecho aparentemente natural nada más que eso? El naturalismo sería claro al respecto: no hay nada más. El supranaturalismo necesitaría recurrir a elementos milagrosos para percibir ahí la acción de Dios.

Leamos, no obstante, este mismo episodio a la luz de Mt 25, 31ss. Todos lo recordamos: "venid a mí benditos de mi Padre, porque tuve hambre y me disteis de comer, tuve frío y me cubristeis, estuve enfermo y me visitasteis, etc...».

El panenteísmo dialéctico, en consecuencia, nos ofrece una clave bien distinta: el encuentro natural entre aquellos que se ayudan, se cuidan y se aman está 
preñado de una presencia de Dios que, manteniendo la plena autonomía y la plena alteridad de las personas libres que interaccionan —el enfermo es el enfermo, el que ayuda es el que ayuda - sin embargo, canaliza la verdadera fuerza del amor divino que presencializa en la inmanencia de la creación al propio Dios trascendente: «¡a mí me lo hicisteis!». Y esto para sorpresa de tirios y troyanos. Porque la acción transformadora de la gracia de Dios alcanza al desvalido a través del acto de compasión de quien libremente decide ayudarlo. La gracia actúa, pues, como verdadera «acción» de Dios haciendo que la libertad humana haga el bien. Y es esta una acción que, siendo obra de la gracia de Dios, de ninguna manera deja de ser obra igualmente de la libertad humana. Y a la inversa: siendo una obra libremente querida por quien realmente la protagoniza —el samaritano- es, en su último nivel de profundidad máxima, verdadera acción salvadora de Dios.

Y esto es así porque la relación de absoluta dependencia que la creación tiene con su Creador supone que a mayor presencia de Dios más la criatura es ella misma y, al revés, a mayor autonomía de la creación mayor presencia y acción de Dios en ella.

La acción y la presencia de Dios inundan la creación sin anegarla, la envuelven por dentro y por fuera sin asfixiarla, la atraviesan sin descoyuntarla. Antes bien, como acabo de indicar, cuanta más presencia de Dios hay en la creación más autónoma y libre es la creación. Por eso, cuanto más actúa Dios en ella más actúa en plena libertad ella misma. Y Dios actúa en los tres modos del tiempo secuencial: en el pasado, presente y futuro de su creación. Ni el naturalismo ni el supranaturalismo aciertan, pues, con la clave decisiva de la cuestión. El panenteísmo dialéctico apunta, a mi juicio, mucho mejor en la dirección correcta.

Universidad Pontificia Comillas

castelao@comillas.edu

Pedro Castelao

[Artículo aprobado para publicación en diciembre de 2016] 